This manuscript is accepted for publication at Psychological Medicine and is available online: https://doi.org/10.1017/S0033291722004019

\title{
Increased affective reactivity to daily social stressors is associated with more severe psychotic symptoms in youths with 22 q11.2 deletion syndrome
}

\author{
Laura Ilen $^{\mathrm{a} *}$, Clémence Feller ${ }^{\mathrm{a}}$, Stephan Eliez ${ }^{\mathrm{b}, \mathrm{c}}$, Maude Schneider ${ }^{\mathrm{a}}$
}

${ }^{a}$ Clinical Psychology Unit for Intellectual and Developmental Disabilities, Faculty of Psychology and Educational Sciences, University of Geneva, Geneva, Switzerland

bepartment of Genetic Medicine and Development, Faculty of Medicine, University of Geneva, Geneva, Switzerland 'Developmental Imaging and Psychopathology Lab Research Unit, Faculty of Medicine, University of Geneva, Geneva, Switzerland

\section{*Corresponding author:}

Laura Ilen

Clinical Psychology Unit for Intellectual and Developmental Disabilities

Faculty of Psychology and Educational Sciences

University of Geneva

40, Boulevard du Pont-d'Arve

1205 Geneva

Switzerland

Laura.Ilen@unige.ch

Word count: 5473 
Funding Statement: This work was supported by an Ambizione grant from the Swiss National Science Foundation to MS (PZ00P1_174206), a research grant from the Swiss National Science Foundation to SE (320030_179404) and a grant from the National Center of Competence in Research (NCCR) “Synapsy-The Synaptic Bases of Mental Diseases” (51NF40-185897). 
Abstract (242 words)

Background. Increased reactivity to minor stressors is considered a risk factor for psychosis, especially in vulnerable individuals. In the present study, we investigated affective and psychotic stress reactivity as well as its link with psychotic symptoms and psychopathology in youths with $22 \mathrm{q} 11.2$ deletion syndrome (22q11DS), a neurogenetic condition associated with a high risk for psychosis.

Methods. A 6-day Ecological Momentary Assessment (EMA) protocol was used to assess perceived daily-life stress as well as affective and psychotic reactivity to stress in participants with 22q11DS ( $n=$ 38 , age $=18.4)$ and healthy controls $(\mathrm{HC} ; n=53$, age $=19.1)$. Psychotic symptoms, general psychopathology and coping strategies were also assessed through clinical interviews and questionnaires.

Results. Participants with 22q11DS reported higher levels of perceived social stress ( $b=0.21, p=0.036)$ but lower levels of activity-related stress $(b=-0.31, p=0.003)$ in their daily lives compared to HC. The groups did not differ in affective or psychotic reactivity to stress, but individuals with 22q11DS who reported increased affective reactivity to social stressors showed more severe positive psychotic symptoms $\left(r_{s}=0.505, p=0.008\right)$. Finally, avoidance coping strategies moderated the association between stress and negative affects.

Conclusions. Our results suggest an increased vulnerability for daily social stress in youths with 22q11DS, and link elevated social stress reactivity to heightened psychotic symptom severity. Given the high risk for psychosis in 22q11DS, interventions should focus on reducing social stress and developing adaptive coping strategies.

\section{Keywords}

Psychological stress; Psychosis; Psychopathology; Coping Skills; Ecological Momentary Assessment 


\section{Introduction}

Stress likely plays a role in the onset of various mental disorders, including psychosis, notably in vulnerable individuals (Corcoran et al., 2003; Kessler et al., 2010). Besides major life events, minor daily-life stressors (daily hassles) are associated with the development of psychotic symptoms and more broadly with psychopathology (Kanner, Coyne, Schaefer, \& Lazarus, 1981; Tessner, Mittal, \& Walker, 2011). Sensitization has been proposed as a mechanism linking earlier stress exposure to later mental health issues; the stress sensitization model posits that past exposure to environmental stress can alter stress regulation, resulting in more intense responses to minor stressors, and heightens the risk for developing psychiatric disorders (Collip, Myin-Germeys, \& Van Os, 2008). Earlier studies have shown that daily stressors activate the hypothalamic-pituitary-adrenocortical (HPA)-axis by increasing cortisol levels (Collip et al., 2011), and that the stress-cortisol relationship is mediated by negative affects (NA) (Jacobs et al., 2007). Therefore, measuring negative affective responses to minor stressors could provide indirect evidence of how sensitive individuals are to stress. Moreover, the strategies that are used to cope with these minor stressors might contribute to the intensity of stress responses (Sladek, Doane, Luecken, \& Eisenberg, 2016) and be associated with psychopathological symptoms (Compas et al., 2017).

Ecological Momentary Assessment (EMA), a structured diary method that enables repeated assessments in the flow of daily life is a particularly well-suited technique to investigate affective responses to stress (Myin-Germeys et al., 2018). EMA studies have shown that perceived stress is associated with increased NA (e.g., Myin-Germeys, van Os, Schwartz, Stone, \& Delespaul, 2001), thus affective reactivity to stress has been defined as an increase in NA in relation to minor stressors. Similarly, an increase in momentary psychotic experiences related to stress is defined as psychotic reactivity to stress (Myin-Germeys, Delespaul, \& van Os, 2005). Altered reactivity to stress is seen as a vulnerability marker for psychopathology, particularly for psychosis (Myin-Germeys et al., 2003; MyinGermeys \& van Os, 2007; Vaessen et al., 2017). It is thought that heightened sensitivity to stress at the "micro-level" (as measured in the moment in daily life) may lead to the persistence of psychotic symptoms at the "macro-level", and subsequently to the development of psychosis (Collip et al., 2013). Indeed, elevated affective and psychotic reactivity to stress have often been reported in patients with psychosis, their siblings and individuals at clinical high-risk for psychosis (CHR) (e.g., Lataster, Collip, Lardinois, van Os, \& Myin-Germeys, 2010; Myin-Germeys et al., 2001; Palmier-Claus, Dunn, \& Lewis, 2012). Notably, it has been suggested that exposure to social stress (e.g., social-evaluative threat) could play a role in the development of psychosis in vulnerable individuals (Jones \& Fernyhough, 2007). A recent review of EMA studies showed that individuals with schizophrenia experience increased social stress in their daily lives (Mote \& Fulford, 2020). Similarly, heightened social stress and increased reactivity to social stressors have been reported in CHR individuals (Palmier-Claus et al., 2012). Moreover, Millman et al. (2018) recently showed an association between perceived social stress and 
more severe positive psychotic symptoms in CHR adolescents, supporting the role of social stress in psychosis. To further examine whether alterations in reactivity to (social) stress are related to the severity of subthreshold psychotic symptoms in vulnerable individuals, the study of a population at high risk for psychosis, such as individuals with chromosome 22q11.2 deletion syndrome (22q11DS), appears highly valuable.

22q11DS is a neurogenetic condition, resulting from a 1.5-3 megabase deletion on the long arm of chromosome 22, which has an estimated prevalence of 1:2148 live births (Blagojevic et al., 2021). The syndrome is associated with a high prevalence of psychiatric comorbidities, notably schizophreniaspectrum disorders (Schneider et al., 2014). Individuals with 22q11DS are thought to experience high levels of chronic stress from childhood (Beaton \& Simon, 2011) and use less adaptive coping strategies compared to individuals from the general population (Armando et al., 2018; Ilen et al., 2022). Furthermore, indirect evidence of HPA-axis dysregulation, demonstrated as alterations in cortisol levels or in pituitary volume (Armando et al., 2018; Jacobson, Bursch, \& Lajiness-O'Neill, 2016; Sanders, Hobbs, Stephenson, Laird, \& Beaton, 2017; Sandini et al., 2020; van Duin et al., 2019), could point towards altered stress reactivity in 22q11DS as well as the role of stress in the development of psychopathology (Ilen et al., 2022). However, affective and psychotic reactivity to daily-life stress has only been investigated once in a sample of adults with 22q11DS (Schneider et al., 2020). This study did not show alterations in stress reactivity in adults with 22q11DS compared to healthy controls (HC), but suggested that they could experience minor events as more stressful. However, the sample of this study, consisting of relatively high-functioning adults, was not fully representative of the 22q11DS population. Given that adolescence and emerging adulthood is a period characterized by increased stress reactivity (especially towards social stressors) (van den Bos, De Rooij, Miers, Bokhorst, \& Westenberg, 2014) as well as heightened risk for the onset of mental disorders (Kessler et al., 2007), investigating stress reactivity and its link with psychopathology is particularly relevant at this age. In light with high social anxiety (Schneider et al., 2014), impairments in social skills (Shashi et al., 2012) and deficits in social cognition (for a review, see Milic, Feller, Schneider, Debbané, \& Loeffler-Stastka, 2021) associated with the syndrome, social stress may be specifically important to investigate in youths with 22q11DS.

In the present study, the aim was to use EMA to investigate affective and psychotic reactivity to daily-life stressors (social, activity-related and event-related stress) in adolescents and young adults with 22q11DS compared to HC. Moreover, we aimed to examine whether the effect of stress on NA/psychotic experiences is moderated by non-adaptive coping strategies, and whether stress reactivity is related to psychotic symptoms or more general psychopathology in 22q11DS. We hypothesized that the 22q11DS group would show higher levels of perceived stress and increased reactivity to stress compared to $\mathrm{HC}$, and that heightened stress reactivity would be associated with more severe psychopathology in 22q11DS. 


\section{Methods}

\section{Sample}

Forty participants ( 22 males, 18 females) with a confirmed diagnosis of 22q11.2 deletion syndrome aged 12-28 years participated in the present study. Data were collected since August 2018 through the Swiss 22q11DS longitudinal cohort. The 22q11.2 deletion was confirmed using microarray analysis. 55 HC (27 males, 28 females) aged 12-25 years were recruited through the siblings of the participants with 22q11DS and within the Geneva local community. Sample characteristics are shown in Table 1. Of note, part of our sample (i.e., $n=2122 \mathrm{q} 11 \mathrm{DS}$ and $n=32 \mathrm{HC}$ ) overlapped with that of our earlier study (Ilen et al., 2022). There was no overlap with the earlier study investigating stress reactivity in adults with 22q11DS (Schneider et al., 2020).

All participants had to have sufficient verbal and intellectual skills, and at least one parent/caretaker available to participate in the study. For participants with an IQ score within the intellectual disability range $(n=16)$, reading comprehension as well as comprehension about the principles of a Likert scale was clinically assessed during the EMA briefing session and it was ensured that the participants understood and were able to answer all the questions. Exclusion criteria for $\mathrm{HC}$ were 1) premature birth, 2) first-degree relative with developmental disorder (with the exception of a de novo 22q11.2 deletion), 3) neurological disorder, 4) history of psychiatric disorder or 5) history of learning/language disorder requiring treatment. All participants and caretakers gave their written consent. Participants received a financial compensation of $100 \mathrm{CHF}$ for participating in a larger study including also additional measures. The study was approved by the Cantonal Research Ethics Committee of Geneva (CCER).

\section{Materials}

\section{Ecological Momentary Assessment (EMA)}

Smartphone-based EMA was used to evaluate participants' affects, momentary psychotic experiences and perceived stress in daily-life context. EMA data collection and measures are detailed in supplementary material.

\section{Questionnaires}

The use of coping strategies was evaluated with two self-reported questionnaires. In the Cognitive Emotion Regulation Questionnaire (CERQ) (Garnefski, Kraaij, \& Spinhoven, 2001), the use of adaptive (acceptance, positive refocusing, refocus on planning, positive reappraisal, putting into perspective) and non-adaptive (self-blame, rumination, catastrophizing, and blaming others) strategies in response to negative events is examined on a 5-point Likert-scale ( $1=$ almost never, $5=$ almost always). The Adolescent Coping Orientation for Problem Behaviors (A-COPE) (Patterson \& McCubbin, 1987) evaluates how often on a 5-point Likert-scale ( $1=$ never, $5=$ most of the time) participants use different 
behaviors when confronted with difficulties or feeling tense. Studies using the A-COPE operationalized the underlying dimensions of coping behaviors in different ways. In this study, we used a factor structure derived from an European (Spanish) sample, which grouped different behaviors in eight coping styles: Engaging in demanding activities, Seeking diversion, Seeking family support, Positive re-appraisal, Seeking spiritual support, Escaping, Ventilating feelings and Searching for friendship (Forns et al., 2013). According to a second-order factor analysis, the authors considered the first five strategies as Approach focus of coping (respective factor loadings $=.73, .71, .67, .64$ and .32 ) and the three last strategies as Avoidance coping $(.78, .66, .61)$ (Forns et al., 2013). However, it should be noted that there is no consensus on the second-order grouping of items; notably, seeking friends' support has previously been considered as an adaptive coping strategy (Patterson \& McCubbin, 1987). Therefore, the eight dimensions were also investigated separately to get a clearer picture about the use of different strategies.

General psychopathology was measured through a parent-reported questionnaire: the Child Behavior Checklist (CBCL) or the Adult Behavior Checklist (ABCL) (Achenbach \& Rescorla, 2001, 2003). The age-normalized T-scores of total psychopathology and externalizing and internalizing subscales were used in the analyses. In a supplementary analysis, the anxious-depressed dimension was also used.

\section{Clinical assessment}

A comprehensive clinical assessment was conducted with participants with 22q11DS to examine the presence of DSM diagnoses (see supplementary material). Psychiatric comorbidity was measured as the sum of current psychiatric diagnoses (Sandini et al., 2020). Moreover, the Structured Interview for Psychosis-Risk Syndromes (SIPS) (Miller et al., 2002) was used to assess (attenuated) positive and negative psychotic symptoms.

The Global Assessment of Functioning (GAF) and the Childhood Global Assessment Scale (CGAS) (Shaffer et al., 1983) were used as global measures of functioning.

\section{Cognitive assessment}

Intellectual functioning was assessed with Weschler Intelligence Scale for Children (Wechsler, 2014) or Adults (Wechsler, 2008).

\section{Statistical analyses}

Most of the analyses were conducted using Stata 16 (StataCorp, 2019). The likelihood ratio tests (LRTs) and Spearman rank correlations were conducted in R version 3.6.3 (R Core Team, 2020) using nlme (Pinheiro, Bates, \& R Core Team, 2022) and ppcor (Kim, 2015) packages. Moreover, potentially influential bivariate outliers based on the Cook's distance ( $\mathrm{Di}>1.0$ or other comparatively large values detected from a graph) were detected using $\mathrm{R}$. The analyses were repeated by removing these outliers, and the results remained unchanged. In the correlation analyses, stress reactivity values $>3$ SD from 
mean were defined as univariate outliers. Removing outliers, most correlations remained unchanged. Therefore, in the main document, the results from the full sample are reported. Results of the correlations without outliers are reported in a supplement.

The EMA data have a two-level structure, with repeated measurements (level 1) nested within individuals (level 2). The models were corrected for autocorrelation between residuals using an AR(1) autocorrelation structure.

Group comparisons for non-EMA variables were done using Mann-Whitney $U$ tests or chi-square tests. For time-invariant EMA variables (e.g., \% time spent alone) group comparisons were performed using multiple linear regression models. For time-varying EMA variables (e.g., NA), group comparisons were performed using multilevel regression models with random intercepts. For the analyses conducted on the EMA variables, age, gender and EMA period (i.e., period during which each participant took part in the EMA assessment; 1. school/work; 2. holidays; or 3. lockdown due to covid-19) were included as covariates. Of note, since lower IQ is part of 22q11DS phenotype, we did not use IQ as a covariate in between-group analyses since this would have removed some of the variance inherent to the diagnosis (Dennis et al., 2009). However, IQ was added as a covariate in the within-group analyses (see below).

To examine associations between stress and NA/momentary psychotic experiences, separate multilevel regression models with random intercepts and random slopes were estimated, with each stress variable as the independent variable and NA/momentary psychotic experiences as the dependent variable using the MIXED command. The stress $\mathrm{x}$ group interaction was added to the model to investigate possible group differences in stress reactivity, again controlling for age, gender and EMA period. To examine whether coping moderated the effect of stress on NA, the score of non-adaptive coping was included into the model. For the CERQ, the non-adaptive coping subscale was used, whereas for the A-COPE, the subscale of avoidance coping as well as all the avoidant strategies were investigated separately. To be able to compare models with different predictors, LRTs using ML estimation were used to assess model fit for two- (stress $\mathrm{x}$ coping) and three-way (stress $\mathrm{x}$ coping $\mathrm{x}$ group) interactions.

Finally, to examine correlations between stress reactivity and psychopathology in 22q11DS, stress reactivity variables were created calculating momentary-level within-person beta coefficients of the association between stress and NA for each participant (three beta coefficients per participant) (see Kramer et al., 2014). Social stress reactivity was not calculated for participants if they reported being in a company of others on less than four beeps $(n=4)$. Moreover, the stress reactivity variables could not be calculated due to collinearity issues for a few participants (social stress, $n=3$; activity stress, $n=2$; event stress, $n=2$ ). Spearman rank correlations between stress reactivity and psychopathology variables were conducted, controlling for the effects or age, sex, IQ and EMA period. Multiple comparisons were corrected with Benjamini-Hochberg (B-H) correction (Thissen, Steinberg, \& Kuang, 2002).

The current study was co-registered during the data collection (10.17605/OSF.IO/3W4C6; 10.17605/OSF.IO/4V2ZA). Deviations from the co-registration are detailed in supplementary material. The data set is publicly available through the YARETA data preservation system. 


\section{Results}

\section{Sample characteristics and group differences in demographic variables}

From the total sample $(n=95)$, four participants (two from each group) provided less than 16 valid responses ( $<33.3 \%$ of total number of beeps) and were therefore excluded from the study. The final sample consisted of 91 individuals ( $n=38$ participants with 22q11DS with 1132 valid responses, $n=53$ HC with 1727 valid responses). Due to difficulties in understanding the meaning of questions related to past events, responses for these questions were excluded for one participant with 22q11DS. Detailed information about compliance of valid participants is shown in Table 1. The groups did not differ in terms of compliance, but the 22q11DS group had a significantly longer mean response time than HC. Note that IQ was not significantly associated with compliance rate in participants with 22q11DS $\left(r_{s}(37)\right.$ $=-0.116, p=0.493)$.

Characteristics of participants are shown in Table 1. Most demographic variables did not differ between the groups. Compared to HC, participants with 22q11DS had a significantly lower mean IQ, in line with previous literature (De Smedt et al., 2007). Of note, age or sex were not associated with stress in any context or any of the stress reactivity measures (see supplementary material).

\section{Group differences in EMA measures}

Group differences in EMA measures are shown in Table 2. The groups did not significantly differ in the proportion of time spent alone during the period of evaluation. However, participants with 22q11DS reported being less often engaged in work/school-related activities and activities related to social contact compared to HC. On the contrary, participants with 22q11DS reported doing leisure activities more frequently than $\mathrm{HC}$.

Levels of positive affect (PA) and NA did not significantly differ between the groups. However, participants with 22q11DS reported higher levels of momentary psychotic experiences than HC.

Participants with 22q11DS reported higher levels of social stress but lower levels of activity stress compared to HC. A supplementary analysis was conducted to investigate whether the global level of functioning was associated with activity-related stress in individuals with 22q11DS, but no significant association was observed $(b=0.004$ ( $95 \%$ confidence interval $(\mathrm{CI})-0.01$ to 0.018$), p=0.533)$. Finally, the level of event stress did not significantly differ between the groups.

\section{Affective and psychotic reactivity to stress}

In the entire sample, NA was significantly associated with all stress variables (Table 3). However, the stress $\mathrm{x}$ group interaction was not significant for any stress variable, indicating no significant differences in affective reactivity to stress between the two groups (Figure 1). In the clinical group, a post-hoc 
analysis investigating the potential impact of SSRI medication on stress reactivity was conducted and no impact of medication status was detected (see supplementary material).

For all participants, the level of momentary psychotic experiences was not associated with stress in any context. Moreover, the stress x group interaction on psychotic experiences was not significant for any stress variable (Table 3).

As the results indicate a link between stress and NA, but not between stress and momentary psychotic experiences, the following analyses were only conducted for the affective reactivity to stress.

\section{Effect of coping strategies}

The 22q11DS group reported using less adaptive coping strategies to regulate their emotions but did not differ from HC regarding the use of non-adaptive coping (CERQ) (Table 1). Moreover, when investigating more concrete coping behaviors (A-COPE), several strategies were reported to be used less often by participants with 22q11DS: engaging in demanding activities, positive re-appraisal, ventilating feelings and searching for friendship. On the other hand, they reported more often seeking family support. The use of other strategies did not significantly differ between the groups.

Examining possible moderating effect of coping on the stress-NA association, LRT showed no evidence that three-way interaction (by adding the group to the interaction) improved the model fit, so the moderating effect of coping was examined for the whole group using a two-way interaction (see Table 3). A-COPE avoidance coping positively moderated the effect of social stress and event stress on NA, but not the effect of activity stress on NA. When examining different strategies separately, a more frequent use of escaping and ventilating feelings moderated the effect of event stress on NA, and ventilating feelings moderated the effect of social stress on NA. Searching for friendship did not have an effect on stress reactivity. Finally, CERQ non-adaptive coping did not moderate the effect of any of the stress variables on NA.

\section{Correlations between affective reactivity to stress and psychopathology}

Correlations between stress reactivity and psychopathology variables are illustrated in Figure 2. Affective reactivity to social stress was significantly associated with the severity of SIPS positive symptoms $\left(r_{s}(30)=0.505, p=0.008\right.$; B-H threshold $\left.=0.0083\right)$. Affective reactivity to social stress was also associated with negative symptoms, but the association did not survive the multiple comparison correction $\left(r_{s}(30)=0.516, p=0.007\right.$; B-H threshold $\left.=0.0042\right)$. Moreover, we observed associations between activity stress reactivity and SIPS positive symptoms $\left(r_{s}(35)=0.372, p=0.039\right.$; B-H threshold $=0.0042)$ as well as between event stress reactivity and SIPS negative symptoms $\left(r_{s}(34)=0.410, p=\right.$ 0.025; B-H threshold $=0.0042$ ), but they did not survive the B-H correction.

When investigating associations between affective reactivity to stress and more general psychopathology, we observed that either the number of psychiatric comorbidities or other measures of general psychopathology did not significantly correlate with stress reactivity. Finally, a supplementary 
analysis showed that anxio-depressive symptoms were not associated with affective reactivity to social $\left(r_{s}(30)=0.05, p=0.816\right)$, activity-related $\left(r_{s}(35)=-0.14, p=0.448\right)$, or event-related stress $\left(r_{s}(34)=\right.$ $0.26, p=0.173)$. 


\section{Discussion}

Our results indicate that adolescents and young adults with 22q11DS report higher levels of perceived social stress but lower levels of activity-related stress in their daily lives compared to HC. Contrary to our hypotheses, the 22q11DS group did not show increased affective or psychotic reactivity to daily stressors. However, increased affective reactivity to social stress was associated with more severe psychotic symptoms in the 22q11DS group. Finally, participants with 22q11DS differed from HC on the use of several coping strategies, with a tendency to use less adaptative strategies. The use of avoidance coping moderated the stress-NA association in daily life.

\section{Perceived stress}

As expected, due to the high prevalence of social anxiety previously described in the syndrome (Schneider et al., 2014), participants with 22q11DS reported higher levels of daily social stress (i.e., their current social context is subjectively experienced as more negative) than HC. The conflicting results with previous findings (Schneider et al., 2020) could be explained by age differences between the samples: it is likely that adolescents and young adults report more intense social stress than older adults, knowing that the period of adolescence is particularly susceptible to social evaluation (van den Bos et al., 2014). In the general population, better social skills have been associated with lower stress (Segrin, Hanzal, Donnerstein, Taylor, \& Domschke, 2007), so social skills deficits in youths with 22q11DS, together with high social anxiety and impaired social cognition (Milic et al., 2021; Schneider et al., 2014; Shashi et al., 2012), could contribute to a more negative experience of their social interactions. In 22q11DS, high rates of autism spectrum disorders (ASD) and subthreshold autistic symptoms are reported (Vorstman et al., 2006), which may contribute to elevated interpersonal stress in daily life. Indeed, a recent study reported high levels of subjective daily-life stress, including social stress, in individuals with ASD (van der Linden et al., 2021). However, it should be noted that in 22q11DS, the findings regarding perceived social stress are not necessarily consistent across samples, potentially pointing towards significant inter-individual variability (Feller, Ilen, Eliez, \& Schneider, 2022). Indeed, one factor contributing to the intensity of social stress may be the impact of previous, negative social interactions, such as bullying victimization, which is more frequent in youths with special needs, including those with ASD (Blake, Lund, Zhou, Kwok, \& Benz, 2012; Maiano, Normand, Salvas, Moullec, \& Aimé, 2016). More qualitative investigation of the types of social situations perceived as stressful by youths with 22q11DS is important to provide valuable leads for targeted interventions.

On the contrary, participants with 22q11DS reported lower levels of activity-related stress than HC, which can likely be explained by the different types of activities reported by the groups. Indeed, we observed, in line with earlier results (Schneider et al., 2020), that individuals with 22q11DS were less often engaged in activities requiring a certain level of effort (i.e., school/work) or in social contact. The 
reduced time spent on difficult/unpleasant activities and increased time spent on leisure activities potentially decreases the number of opportunities to experience stressful events in daily life. This could offer an explanation for the current findings of similar levels of event-related stress between groups, challenging previous findings (Schneider et al., 2020). It is also possible that the various confinement measures due to the COVID-19 pandemic, during which a proportion of the participants was assessed, explain why some of the youths were less exposed to stressful daily-life events, especially social ones.

\section{Stress reactivity and link with psychopathology}

In line with previous literature (Myin-Germeys et al., 2001), we observed a significant increase in NA in relation to stress in all contexts. However, contrary to our hypothesis, the increase was similar for both groups, indicating that adolescents and young adults with 22q11DS did not show increased reactivity to daily-life stress. Our results replicate the previous findings of Schneider et al. (2020), conducted on a sample of adults with 22q11DS. On the other hand, they do not correspond to previous findings of heightened affective or psychotic reactivity to stress in other CHR individuals (van der Steen et al., 2017), and are not consistent with previous indirect findings of HPA-axis dysregulation in 22q11DS in children or adult samples, possibly suggesting altered stress reactivity (Armando et al., 2018; Jacobson et al., 2016; Sanders et al., 2017; Sandini et al., 2020; van Duin et al., 2019). In adolescents and young adults, we recently showed no evidence of altered daily cortisol in 22q11DS (Ilen et al., 2022). The mixed findings could possibly be explained by high inter-individual variability within individuals with 22q11DS. In the current study, we effectively observed a relatively high variation in affective reactivity to stress within the 22q11DS group, which could indicate increased stress reactivity in a subgroup of participants. Therefore, inter-individual variability in stress reactivity should be further investigated in youths with 22q11DS, also through physiological measures, to draw stronger conclusions.

A potential explanation for the inter-individual differences in stress reactivity could be the use of medication. For instance, earlier literature has shown the efficacy of long-term SSRI treatment in reducing cortisol reactivity to stress in chronic post-traumatic stress disorder (Vermetten et al., 2006). Positive effects of SSRIs on cognition and brain development have also recently been shown in youths with 22q11DS (Mancini et al., 2021). In our study, participants with SSRI medication at the time of testing did not differ from those without SSRIs in terms of affective reactivity to stress, even when dose equivalent and duration of treatment were added as covariates. However, the subsample of participants treated with SSRIs was quite small, so it would be interesting to further study the impact of medication, including SSRIs, on stress reactivity and, eventually, on the risk for psychopathology in vulnerable populations with a larger sample size. Another possible factor explaining inter-individual differences in stress reactivity could be the exposure to (early-life) stress or trauma, as higher levels of childhood trauma have been associated with increased stress reactivity in other vulnerable populations (Paetzold et al., 2021; Rauschenberg et al., 2017). It is thought that individuals with 22q11DS are more frequently 
exposed to stress than their peers, due to the different challenges (e.g., medical, cognitive and social) that they may face from childhood onwards (Beaton \& Simon, 2011). In particular, 22q11DS is associated with various medical issues, including congenital heart disease, palatal abnormalities and immunodeficiency (Swillen \& McDonald-McGinn, 2015), and medical procedures could be important sources of stress for certain children with 22q11DS. The role of stressful and traumatic life events on stress reactivity in 22q11DS is worth exploring in future studies.

Inter-individual differences in stress reactivity are potentially important to determine which individuals are more prone to develop mental health issues and psychosis in general. Increased reactivity to momentary stress is thought to be a mechanism that can lead to persistent "macro-level" symptoms and heighten the risk of a transition to mental health issues (Collip et al., 2013; Vaessen et al., 2017). At the cross-sectional level, we indeed observed an association between increased affective reactivity to social stressors at the momentary level and more severe ("macro-level") psychotic symptoms. The association was notably significant for positive symptoms of psychosis, in line with earlier findings in individuals with psychosis (Lataster, Valmaggia, Lardinois, van Os, \& Myin-Germeys, 2013). This is the first study to demonstrate an association between social stress reactivity and psychotic symptoms in 22q11DS, even though social stress has previously been linked with more severe psychotic symptoms in other CHR populations (Millman et al., 2018; Veling, Pot-Kolder, Counotte, van Os, \& van der Gaag, 2016) and elevated (social) stress reactivity has been associated with increased momentary psychotic experiences in early psychosis (Reininghaus et al., 2016). Altogether, it suggests that increased stress sensitivity over long periods of time could create a snowball effect on the development of mental health symptoms: heightened moment-to-moment reactivity to stress might increase the vulnerability for developing psychotic symptoms and ultimately psychosis in vulnerable individuals, such as youths with 22q11DS. However, this remains hypothetical, as we used a cross-sectional design, and the causal relationship between stress reactivity and psychopathology was not investigated.

Although our results show more severe symptoms in youths with 22q11DS who are more reactive to stress, stress does not appear to increase momentary psychotic experiences in daily life (given the lack of association between stress and psychotic experiences measured through EMA). It is possible that a direct link between stress and momentary psychotic experiences could be observed in people who are more symptomatic, and that our results would therefore be explained by the fact that most of our participants neither had psychosis or CHR. Moreover, although only two participants with 22q11DS had a diagnosis of psychotic disorder, several participants used an antipsychotic medication to treat psychotic symptoms or anxiety. As the treatment likely attenuates the intensity of symptoms, it is possible that it partially explains the lack of relationship between stress and momentary psychotic experiences.

\section{Coping strategies}


Interestingly, we replicated earlier findings (Armando et al., 2018) regarding the reduced use of adaptive coping in 22q11DS using the CERQ, which measures more abstract emotion regulation strategies. Some differences also emerged on the A-COPE questionnaire, which measures more concrete coping behaviours, such as a lower use of positive re-appraisal or engagement in demanding activities. In terms of non-adaptive strategies, youths with 22q11DS reported "escaping" from their problems less often than $\mathrm{HC}$, which could be explained by the fact that most of the behaviours that were considered as "escaping" were linked with alcohol/tobacco consumption or spending time with a boyfriend/girlfriend, which is less frequent in youths with 22q11DS compared to HC (Feller et al., 2022; Vingerhoets et al., 2019).

We also observed that a more frequent use of strategies that are considered as avoidant (i.e., escaping, ventilating feelings) heightened the affective response to daily-life stressors. Similar findings were not observed for the third strategy "searching for friendships", probably because this type of behaviour can be less clearly considered as an avoidance coping strategy and can also be seen as an adaptive way to cope with stressors (Patterson \& McCubbin, 1987). Even though avoidance can have a short-term impact on decreasing distress, it has been shown to have negative consequences in the long run, such as an increase in negative affects or social withdrawal (Werner \& Gross, 2010). Avoidance is also associated with psychopathology, including depression and anxiety (Compas et al., 2017). Therefore, considering the current results together with previous findings showing that maladaptive coping mediates the association between stress and psychotic symptoms in 22q11DS (Armando et al., 2018), one could tentatively suggest that the use of maladaptive and avoidant coping strategies might increase the risk for psychosis in this vulnerable population through an increase in affective reactivity. In our study, the moderating effect of coping was not specific to the 22q11DS group, indicating that adolescents and young adults in general could likely benefit from using more adaptive coping skills to minimize the impact of daily stressors on negative affective states. However, specific interventions targeting vulnerable youths might be particularly important to implement in order to prevent negative clinical outcomes. These interventions could focus on reducing avoidance through cognitive-behavioural techniques such as exposure, developing more adaptive strategies (e.g. cognitive reappraisal), mindfulness or practicing acceptance (Werner \& Gross, 2010).

\section{Limitations and future directions}

Some methodological limitations should be considered. First of all, the EMA assessment is based on a subjective evaluation of participants and interpretation of items can somewhat differ between persons. Moreover, even though EMA has been used with individuals with mild to moderate intellectual deficit (Wilson et al., 2020), we cannot neglect the fact that understanding certain EMA items could have been difficult to some participants with 22q11DS, especially if they had an intellectual disability. However, to avoid problems related to comprehension or different interpretation of items, all the questions were extensively reviewed with participants during the installation of application. 
Furthermore, as the data were collected at a single timepoint, we were not able to do interpretations regarding the directionality of the stress-NA associations. Future studies could use time-lagged analyses to better understand the causal relationship of stress and affective states. Furthermore, the current study only examined the link between stress reactivity and psychotic symptoms in a cross-sectional way, and longitudinal follow-up of participants would be needed to investigate whether stress reactivity can predict the emergence of psychotic symptoms.

Finally, the use of coping strategies was not assessed at a momentary level (contrary to stress and NA), but at a more general level, which does not offer direct information about the use of specific coping strategies when confronted with stressors in daily-life context. Moreover, as the self-reported questionnaires required evaluating how often in general the youth used different strategies, possible memory or reasoning difficulties may have affected the results more than in the EMA assessment. A limitation of the A-COPE is that the factor-structure of coping styles has been operationalized differently across studies (Forns et al., 2013). To investigate more direct links between momentary stress, coping and NA in daily life, the use of coping strategies should also be assessed using EMA.

\section{Conclusions}

The results of the current study suggest an increased vulnerability for daily social stress in youths with 22q11DS, which could be linked with social anxiety and social impairments associated with the syndrome and should be qualitatively examined to target specific interventions. Furthermore, our results link heightened affective reactivity to social stress with elevated psychotic symptom severity. Given the high risk for psychosis in 22q11DS, interventions should focus on reducing social stress and developing adaptive coping strategies.

The authors assert that all procedures contributing to this work comply with the ethical standards of the relevant national and institutional committees on human experimentation and with the Helsinki Declaration of 1975, as revised in 2008. The study was approved by the Cantonal Research Ethics Committee of Geneva (CCER). 


\section{Acknowledgements}

We would like to warmly thank all the participants for their participation and commitment, as well as the family associations Connect22, Génération 22, Relais 22 and 22q11Europe for their ongoing support. We also thank Charlotte Dubois and Eva Micol for their help in data collection.

Funding Statement: This work was supported by an Ambizione grant from the Swiss National Science Foundation to MS (PZ00P1_174206), a research grant from the Swiss National Science Foundation to SE (320030_179404) and a grant from the National Center of Competence in Research (NCCR) “Synapsy-The Synaptic Bases of Mental Diseases” (51NF40-185897).

\section{Conflicts of Interest: None}

\section{Author Contributions}

Formal analysis: Laura Ilen

Investigation: Laura Ilen, Clémence Feller, Stephan Eliez, Maude Schneider

Methodology: Maude Schneider

Supervision: Maude Schneider

Writing - original draft: Laura Ilen

Writing - review and editing: Laura Ilen, Maude Schneider, Clémence Feller, Stephan Eliez 

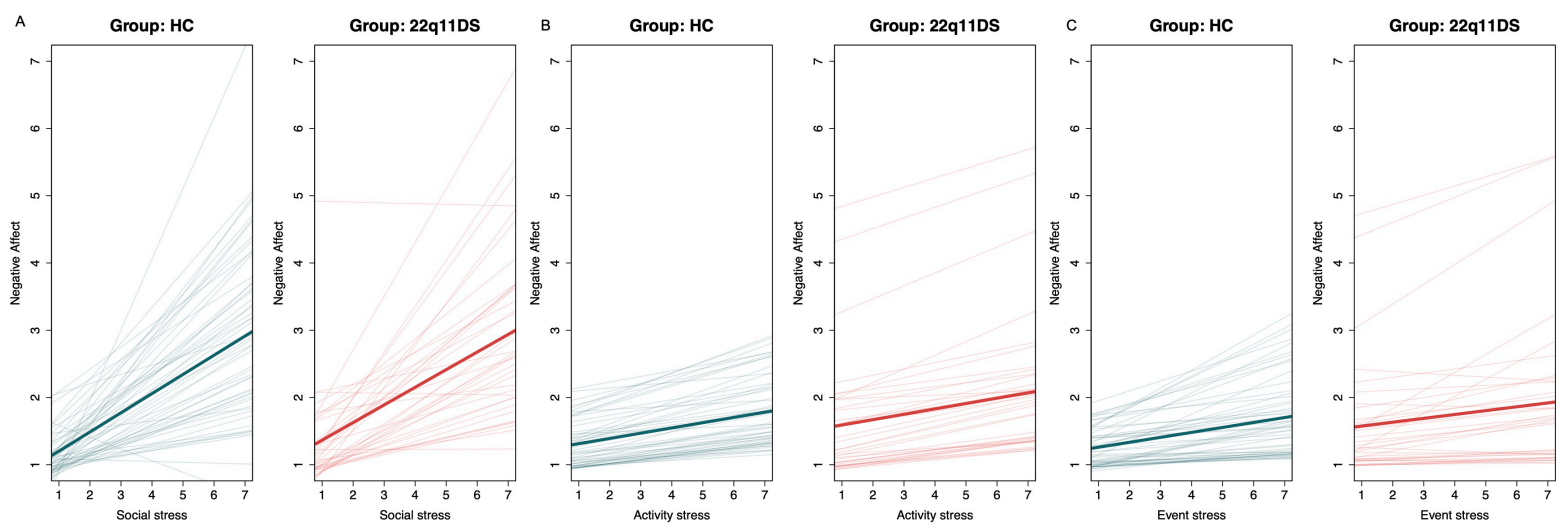

Fig 1. Estimated intercepts and slopes for the two groups of the effect of a) social stress on negative affects ( $n=53 \mathrm{HC}, n=3822 \mathrm{q} 11 \mathrm{DS}$ ), b) activity stress on negative affects ( $n=53 \mathrm{HC}, n=3822 \mathrm{q} 11 \mathrm{DS}$ and c) event stress on negative affects ( $n=53 \mathrm{HC}, n=3722 \mathrm{q} 11 \mathrm{DS})$.

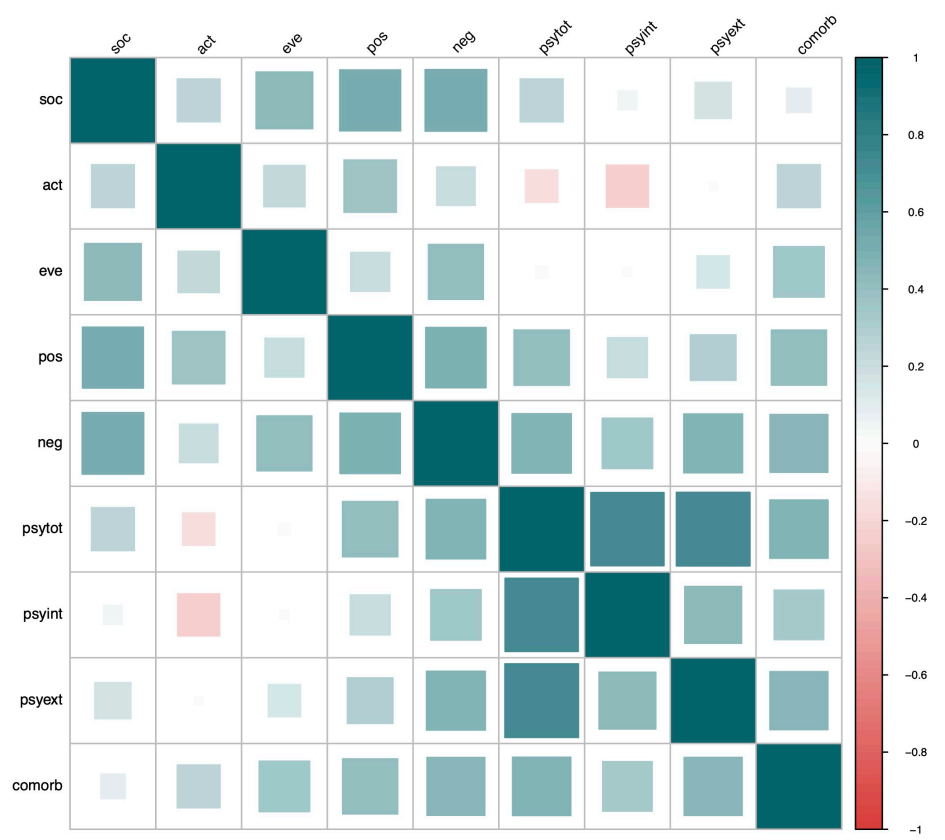

Fig 2. Spearman rank correlations between stress reactivity and psychopathology variables in 22q11DS group, after controlling for age, sex, IQ and period. soc = social stress reactivity; act = activity stress reactivity; eve = event stress reactivity; pos = score of SIPS positive psychotic symptoms; neg = score of SIPS negative symptoms; psytot $=$ score of total psychopathology $(\mathrm{ABCL} / \mathrm{CBCL})$; psyint $=$ score of internal psychopathology $(\mathrm{ABCL} / \mathrm{CBCL})$; psyext = score of external psychopathology $(\mathrm{ABCL} / \mathrm{CBCL})$; comorb $=$ number of psychiatric comorbidities. 
Table 1. Group comparisons of demographic characteristics and variables of interest

\begin{tabular}{|c|c|c|c|c|}
\hline & $\begin{array}{l}\text { Healthy controls } \\
\qquad(\mathrm{n}=\mathbf{5 3})\end{array}$ & $\begin{array}{c}\text { 22q11DS } \\
(\mathrm{n}=38)\end{array}$ & Test statistic & P-value \\
\hline Age in years, mean (S.D.) & $18.42( \pm 3.61)$ & $19.12( \pm 4.88)$ & $Z=-0.26$ & 0.801 \\
\hline $\operatorname{Sex}(n$ M/F $)$ & $25 / 28$ & $21 / 17$ & $X^{2}(1)=0.58$ & 0.446 \\
\hline IQ, mean (S.D.) & $\begin{array}{c}112.25 \\
( \pm 12.18)\end{array}$ & $72.49( \pm 13.73)$ & $Z=7.73$ & $<0.001 * * *$ \\
\hline \multicolumn{5}{|l|}{ EMA $^{\text {a }}$, mean (S.D.) } \\
\hline Completed beeps & $32.58( \pm 7.62)$ & $29.79( \pm 9.34)$ & $T=-1.57$ & 0.12 \\
\hline$\%$ Completed beeps & $67.89( \pm 15.88)$ & $62.06( \pm 19.45)$ & & \\
\hline Response time & $\begin{array}{c}02: 29 \\
( \pm 01: 25)\end{array}$ & $02: 53( \pm 01: 42)$ & $Z=7.92$ & $<0.001 * * *$ \\
\hline \multicolumn{5}{|l|}{ Coping: CERQ, mean (S.D.) } \\
\hline Non-adaptive coping & $34.32( \pm 8.03)$ & $33.58( \pm 10.63)$ & $Z=0.62$ & 0.541 \\
\hline Adaptive coping & $66.55( \pm 16.16)$ & $53.61( \pm 14.72)$ & $Z=3.80$ & $<0.001 * * *$ \\
\hline \multicolumn{5}{|l|}{ Coping: A-COPE, mean (S.D.) } \\
\hline Seeking diversion & $23.47( \pm 6.56)$ & $24.84( \pm 7.21)$ & $Z=-1.08$ & 0.282 \\
\hline Escaping & $8.41( \pm 4.02)$ & $5.74( \pm 2.2)$ & $Z=3.41$ & $<0.001 * * *$ \\
\hline Seeking family support & $18.39( \pm 5.18)$ & $21.05( \pm 3.55)$ & $Z=-2.78$ & $0.005^{* *}$ \\
\hline Seeking friendship & $24.25( \pm 5.13)$ & $20.95( \pm 5.02)$ & $Z=2.8$ & $0.005^{* *}$ \\
\hline Ventilating feelings & $15.74( \pm 4.15)$ & $14.45( \pm 5.01)$ & $Z=1.89$ & 0.059 \\
\hline Positive re-appraisal & $13.57( \pm 3.24)$ & $11.47( \pm 3.1)$ & $Z=2.77$ & $0.005^{* *}$ \\
\hline Seeking spiritual support & $3.85( \pm 2.12)$ & $4.47( \pm 2.68)$ & $Z=-1.43$ & 0.157 \\
\hline $\begin{array}{l}\text { Engaging in demanding } \\
\text { activities }\end{array}$ & $23.51( \pm 5.23)$ & $20.18( \pm 4.94)$ & $Z=2.88$ & $0.004^{* *}$ \\
\hline \multicolumn{5}{|c|}{ Psychopathology: ABCL/CBCL, mean (S.D.) } \\
\hline Total psychopathology & $46.68( \pm 9.82)$ & $61.71( \pm 10.63)$ & $Z=-5.80$ & $<0.001 * * *$ \\
\hline Internalizing psychopathology & $49.28( \pm 10.18)$ & $66.18( \pm 8.32)$ & $Z=-6.62$ & $<0.001 * * *$ \\
\hline Externalizing psychopathology & $46.94( \pm 10.30)$ & $55.79( \pm 9.13)$ & $Z=-3.68$ & $<0.001 * * *$ \\
\hline \multicolumn{5}{|l|}{ Psychotic symptoms: SIPS } \\
\hline Positive symptoms, mean (S.D.) & & $1.07( \pm 1.07)$ & & \\
\hline $\begin{array}{l}\text { Clinical high risk (CHR) for } \\
\text { psychosis, } n(\%)\end{array}$ & & $6(16 \%)$ & & \\
\hline $\begin{array}{l}\text { Negative symptoms, mean } \\
\text { (S.D.) }\end{array}$ & & $2.41( \pm 0.81)$ & & \\
\hline \multicolumn{5}{|l|}{ Diagnosis, $n(\%)$} \\
\hline Mood disorder & & $4(11 \%)$ & & \\
\hline Anxiety disorder & & $17(45 \%)$ & & \\
\hline ADHD & & $17(45 \%)$ & & \\
\hline Psychotic disorder & & $2(5 \%)$ & & \\
\hline PTSD & & $2(5 \%)$ & & \\
\hline Obsessive-compulsive disorder & & $2(5 \%)$ & & \\
\hline Oppositional defiant disorder & & $1(3 \%)$ & & \\
\hline Other $^{b}$ & & $2(5 \%)$ & & \\
\hline Autism screening $\left(\mathrm{SCQ}^{\mathrm{c}} \geq 15\right)$ & & $10(26 \%)$ & & \\
\hline \multicolumn{5}{|l|}{ Psychotropic medication, $n(\%)$} \\
\hline SSRI $^{\mathrm{d}}$ & & $15(39 \%)$ & & \\
\hline $\begin{array}{l}\text { Other antidepressants or mood } \\
\text { stabilizers }\end{array}$ & & $1(2 \%)$ & & \\
\hline Antipsychotics & & $10(26 \%)$ & & \\
\hline Anxiolytics & & $3(7 \%)$ & & \\
\hline Psychostimulants & & $13(34 \%)$ & & \\
\hline
\end{tabular}


$* p<0.05 ; * * p<0.01 ; * * * p<0.001$

aFor EMA variables, age, sex and EMA period were controlled

${ }^{b}$ Other diagnoses include gambling disorder and excoriation disorder

'SCQ = The Social Communication Questionnaire (Rutter, Bailey, \& Lord, 2003)

${ }^{\mathrm{d}} \mathrm{SSRI}=$ selective serotonin reuptake inhibitors

Note: The same participant can have $>1$ diagnoses and medication. For one participant with 22q11DS, information about diagnosis, psychotic symptoms and medication was not available. 
Table 2. Group comparisons of EMA measures, controlling for age, sex and EMA period

\begin{tabular}{lcccc}
\hline & $\begin{array}{c}\text { Healthy controls } \\
(\text { HC; } \mathbf{n}=\mathbf{5 3})\end{array}$ & $\begin{array}{c}\mathbf{2 2 q 1 1 D S} \\
(\mathbf{n}=\mathbf{3 8})\end{array}$ & HC vs. 22q11DS \\
\hline \multicolumn{1}{c}{ mean (S.D.) } & $\boldsymbol{\beta}(\mathbf{9 5} \% \mathbf{\text { CI}})$ & $\boldsymbol{p}$ \\
\hline Positive affects & $3.96( \pm 0.69)$ & $4.04( \pm 1.04)$ & $0.03(-0.33$ to 0.39$)$ & 0.872 \\
Negative affects & $1.45( \pm 0.41)$ & $1.71( \pm 0.97)$ & $0.25(-0.04$ to 0.55$)$ & 0.096 \\
Momentary psychotic & $1.10( \pm 0.21)$ & $1.55( \pm 1.07)$ & $0.43(0.13$ to 0.74$)$ & $0.005^{* *}$ \\
experiences & $37.83( \pm 23.38)$ & $39.35( \pm 25.98)$ & $0.002(-9.99$ to 9.99$)$ & 1.0 \\
\% Time spent alone & $20.84( \pm 18.58)$ & $12.56( \pm 13.39)$ & $-7.42(-12.5$ to -2.34$)$ & $0.005^{* *}$ \\
\% School/work activity & $8.11( \pm 7.58)$ & $6.54( \pm 9.88)$ & $-1.7(-5.39$ to 1.98$)$ & 0.361 \\
\% House-related activity & $23.57( \pm 18.27)$ & $11.49( \pm 20.62)$ & $-12.38(-20.65$ to -4.11$)$ & $0.004^{* *}$ \\
\% Social activity & $46.73( \pm 16.19)$ & $57.44( \pm 17.53)$ & $10.09(3.57$ to 16.62$)$ & $0.003^{* *}$ \\
\% Leisure activity & $15.19( \pm 7.94)$ & $13.51( \pm 6.56)$ & $-1.48(-4.68$ to 1.72$)$ & 0.36 \\
\% Eat/drink activity & $2.45( \pm 4.52)$ & $4.89( \pm 7.61)$ & $2.53(-0.007$ to 5.08$)$ & 0.051 \\
\% Activity: nothing & $1.64( \pm 0.37)$ & $1.87( \pm 0.59)$ & $0.21(0.01$ to 0.41$)$ & $0.036^{*}$ \\
Social stress & $2.69( \pm 0.40)$ & $2.39( \pm 0.59)$ & $-0.31(-0.51$ to -0.1$)$ & $0.003^{* *}$ \\
Activity stress & $3.43( \pm 0.70)$ & $3.35( \pm 0.92)$ & $-0.08(-0.42$ to 0.26$)$ & 0.648 \\
Event stress & & &
\end{tabular}

$* p<0.05 ; * * p<0.01$ 
Table 3. Association of stress with negative affects and psychotic experiences, and the effect of nonadaptive coping in participants with 22q11DS and healthy controls, controlling for age, sex and EMA period

\begin{tabular}{|c|c|c|c|c|}
\hline & & & \multicolumn{2}{|c|}{ LR test t $^{\mathrm{s}}$} \\
\hline & $\beta(95 \% \mathrm{CI})$ & $p$ & $X^{2}(d f)$ & $p$ \\
\hline \multicolumn{5}{|l|}{ Outcome: negative affects } \\
\hline Social stress & $0.26(0.17$ to 0.36$)$ & $<0.001 * * *$ & & \\
\hline Social stress $\mathrm{x}$ group & $-0.03(-0.18$ to 0.12$)$ & 0.694 & & \\
\hline Activity stress & $0.06(0.04$ to 0.09$)$ & $<0.001 * * *$ & & \\
\hline Activity stress $\mathrm{x}$ group & $0.008(-0.4$ to 0.05$)$ & 0.730 & & \\
\hline Event stress & $0.06(0.03$ to 0.08$)$ & $<0.001 * * *$ & & \\
\hline Event stress $x$ group & $-0.02(-0.06$ to 0.03$)$ & 0.482 & & \\
\hline Social stress $\times$ CERQ $^{b} \times$ group & & & $2.94(4)$ & 0.4 \\
\hline Social stress x CERQ $\mathbf{C}^{b}$ & $-0.005(-0.013$ to 0.003$)$ & 0.237 & & \\
\hline Activity stress x CERQ ${ }^{b}$ x group & & & $2.76(4)$ & 0.43 \\
\hline Activity stress x CERQ ${ }^{b}$ & $-0.001(-0.003$ to 0.001$)$ & 0.458 & & \\
\hline Event stress $x$ CERQ $^{b} \times$ group & & & $2.2(4)$ & 0.531 \\
\hline Event stress x CERQ ${ }^{b}$ & $0.002(-0.0005$ to 0.004$)$ & 0.124 & & \\
\hline Social stress $x$ A-COPE ${ }^{a}$ group & & & $3.96(4)$ & 0.266 \\
\hline Social stress $x$ A-COPE ${ }^{a}$ & $0.01(0.003$ to 0.018$)$ & $0.006 * *$ & & \\
\hline Social stress $\mathbf{x}$ Escaping & $0.019(-0.002$ to 0.04$)$ & 0.075 & & \\
\hline Social stress $\mathrm{x}$ Ventilating feelings & $0.022(0.006$ to 0.037$)$ & $0.007 * *$ & & \\
\hline $\begin{array}{l}\text { Social stress x Searching for } \\
\text { friendship }\end{array}$ & $0.011(-0.003$ to 0.025$)$ & 0.124 & & \\
\hline Activity stress $\times$ A-COPE ${ }^{\text {a }}$ x group & & & $3.99(4)$ & 0.263 \\
\hline Activity stress x A-COPE & $0.0006(-0.002$ to 0.003$)$ & 0.610 & & \\
\hline Activity stress $x$ Escaping & $0.003(-0.003$ to 0.009$)$ & 0.331 & & \\
\hline $\begin{array}{l}\text { Activity stress x Ventilating } \\
\text { feelings }\end{array}$ & $0.002(-0.002$ to 0.007$)$ & 0.317 & & \\
\hline $\begin{array}{l}\text { Activity stress } x \text { Searching for } \\
\text { friendship }\end{array}$ & $-0.0009(-0.005$ to 0.003$)$ & 0.641 & & \\
\hline Event stress x A-COPE ${ }^{a}$ x group & & & $1.77(4)$ & 0.622 \\
\hline Event stress x A-COPE ${ }^{\mathrm{a}}$ & $0.003(0.0008$ to 0.005$)$ & $0.006^{* *}$ & & \\
\hline Event stress $x$ Escaping & $0.008(0.002$ to 0.014$)$ & $0.005 * *$ & & \\
\hline Event stress $x$ Ventilating feelings & $0.006(0.001$ to 0.01$)$ & $0.008 * *$ & & \\
\hline $\begin{array}{l}\text { Event stress x Searching for } \\
\text { friendship }\end{array}$ & $0.002(-0.002$ to 0.006$)$ & 0.379 & & \\
\hline \multicolumn{5}{|l|}{ Outcome: psychotic experiences } \\
\hline Social stress & $0.05(-0.02$ to 0.11$)$ & 0.193 & & \\
\hline Social stress $\mathrm{x}$ group & $-0.02(-0.13$ to 0.09$)$ & 0.711 & & \\
\hline Activity stress & $0.007(-0.01$ to 0.03$)$ & 0.541 & & \\
\hline Activity stress $x$ group & $0.01(-0.02$ to 0.05$)$ & 0.445 & & \\
\hline Event stress & $0.01(-0.01$ to 0.03$)$ & 0.401 & & \\
\hline Event stress x group & $-0.006(-0.05$ to 0.03$)$ & 0.761 & & \\
\hline
\end{tabular}

${ }^{*} p<0.05 ; * * p<0.01 ; * * * p<0.001$

${ }^{\mathrm{a} A-C O P E}$ : score of A-COPE avoidance subscale

${ }^{\mathrm{b}} \mathrm{CERQ}$ : score of CERQ non-adaptive subscale

${ }^{\mathrm{c}}$ Likelihood ratio test with ML estimation for stress $\mathrm{x}$ coping $\mathrm{x}$ group interaction 


\section{References}

Achenbach, T. M., \& Rescorla, L. A. (2001). Manual for the ASEBA school-age forms and profiles. Burlington, VT: University of Vermont, Research Center for Children, Youth and Families.

Achenbach, T. M., \& Rescorla, L. A. (2003). Manual for the ASEBA adult forms \& profiles: Burlington, VT: University of Vermont.

Armando, M., Sandini, C., Chambaz, M., Schaer, M., Schneider, M., \& Eliez, S. (2018). Coping strategies mediate the effect of stressful life events on schizotypal traits and psychotic symptoms in 22q11. 2 deletion syndrome. Schizophrenia bulletin, 44(suppl_2), S525-S535. doi: $10.1093 / \mathrm{schbul} / \mathrm{sby} 025$

Beaton, E. A., \& Simon, T. J. (2011). How might stress contribute to increased risk for schizophrenia in children with chromosome 22q11.2 deletion syndrome? Journal of Neurodevelopmental Disorders, 3(1), 68-75. doi:10.1007/s11689-010-9069-9

Blagojevic, C., Heung, T., Theriault, M., Tomita-Mitchell, A., Chakraborty, P., Kernohan, K., . . . Bassett, A. S. (2021). Estimate of the contemporary live-birth prevalence of recurrent 22q11.2 deletions: a cross-sectional analysis from population-based newborn screening. CMAJ Open, 9(3), E802-e809. doi:10.9778/cmajo.20200294

Blake, J. J., Lund, E. M., Zhou, Q., Kwok, O.-m., \& Benz, M. R. (2012). National prevalence rates of bully victimization among students with disabilities in the United States. School psychology quarterly, 27(4), 210. doi:10.1037/spq0000008

Collip, D., Myin-Germeys, I., \& Van Os, J. (2008). Does the concept of "sensitization" provide a plausible mechanism for the putative link between the environment and schizophrenia? Schizophrenia bulletin, 34(2), 220-225. doi:10.1093/schbul/sbm163

Collip, D., Nicolson, N. A., Lardinois, M., Lataster, T., van Os, J., \& Myin-Germeys, I. (2011). Daily cortisol, stress reactivity and psychotic experiences in individuals at above average genetic risk for psychosis. Psychological medicine, 41(11), 2305-2315. doi:10.1017/s0033291711000602

Collip, D., Wigman, J. T., Myin-Germeys, I., Jacobs, N., Derom, C., Thiery, E., . . van Os, J. (2013). From epidemiology to daily life: linking daily life stress reactivity to persistence of psychotic experiences in a longitudinal general population study. PloS one, 8(4), e62688. doi:10.1371/journal.pone.0062688

Compas, B. E., Jaser, S. S., Bettis, A. H., Watson, K. H., Gruhn, M. A., Dunbar, J. P., . . Thigpen, J. C. (2017). Coping, emotion regulation, and psychopathology in childhood and adolescence: A meta-analysis and narrative review. Psychological bulletin, 143(9), 939-991. doi: $10.1037 /$ bul0000110

Corcoran, C., Walker, E., Huot, R., Mittal, V., Tessner, K., Kestler, L., \& Malaspina, D. (2003). The stress cascade and schizophrenia: etiology and onset. Schizophrenia bulletin, 29(4), 671-692. doi:10.1093/oxfordjournals.schbul.a007038

De Smedt, B., Devriendt, K., Fryns, J. P., Vogels, A., Gewillig, M., \& Swillen, A. (2007). Intellectual abilities in a large sample of children with Velo-Cardio-Facial Syndrome: an update. Journal of Intellectual Disability Research, 51(Pt 9), 666-670. doi:10.1111/j.1365-2788.2007.00955.x

Dennis, M., Francis, D. J., Cirino, P. T., Schachar, R., Barnes, M. A., \& Fletcher, J. M. (2009). Why IQ is not a covariate in cognitive studies of neurodevelopmental disorders. Journal of the International Neuropsychological Society, 15(3), 331-343. doi:10.1017/s1355617709090481

Feller, C., Ilen, L., Eliez, S., \& Schneider, M. (2022). Characterizing Daily-Life Social Interactions in Adolescents and Young Adults with Neurodevelopmental Disorders: A Comparison Between Individuals with Autism Spectrum Disorders and 22q11.2 Deletion Syndrome. Journal of autism and developmental disorders. doi:10.1007/s10803-021-05423-9

Forns, M., Kirchner, T., Peró, M., Pont, E., Abad, J., Soler, L., \& Paretilla, C. (2013). Factor structure of the adolescent coping orientation for problem experiences in Spanish adolescents. Psychological reports, 112(3), 845-871. doi:10.2466/03.20.Pr0.112.3.845-871

Garnefski, N., Kraaij, V., \& Spinhoven, P. (2001). Negative life events, cognitive emotion regulation and emotional problems. Personality and Individual differences, 30(8), 1311-1327. doi:10.1016/S0191-8869(00)00113-6 
Ilen, L., Feller, C., Eliez, S., Micol, E., Delavari, F., Sandi, C., . . Schneider, M. (2022). Exploring associations between diurnal cortisol, stress, coping and psychopathology in adolescents and young adults with 22q11. 2 deletion syndrome. Comprehensive Psychoneuroendocrinology, 9, 100103. doi:10.1016/j.cpnec.2021.100103

Jacobs, N., Myin-Germeys, I., Derom, C., Delespaul, P., van Os, J., \& Nicolson, N. A. (2007). A momentary assessment study of the relationship between affective and adrenocortical stress responses in daily life. Biological psychology, 74(1), 60-66. doi:10.1016/j.biopsycho.2006.07.002

Jacobson, D., Bursch, M., \& Lajiness-O'Neill, R. (2016). Potential role of cortisol in social and memory impairments in individuals with 22q11. 2 deletion syndrome. Journal of pediatric genetics, 5(3), 150. doi:10.1055/s-0036-1584549

Jones, S. R., \& Fernyhough, C. (2007). A new look at the neural diathesis--stress model of schizophrenia: the primacy of social-evaluative and uncontrollable situations. Schizophrenia bulletin, 33(5), 1171-1177. doi:10.1093/schbul/sbl058

Kanner, A. D., Coyne, J. C., Schaefer, C., \& Lazarus, R. S. (1981). Comparison of two modes of stress measurement: Daily hassles and uplifts versus major life events. Journal of behavioral medicine, 4(1), 1-39. doi:10.1007/BF00844845

Kessler, R. C., Angermeyer, M., Anthony, J. C., R, D. E. G., Demyttenaere, K., Gasquet, I., . . Ustün, T. B. (2007). Lifetime prevalence and age-of-onset distributions of mental disorders in the World Health Organization's World Mental Health Survey Initiative. World Psychiatry, 6(3), 168-176.

Kessler, R. C., McLaughlin, K. A., Green, J. G., Gruber, M. J., Sampson, N. A., Zaslavsky, A. M., . . . Williams, D. R. (2010). Childhood adversities and adult psychopathology in the WHO World Mental Health Surveys. The British journal of psychiatry, 197(5), 378-385. doi:10.1192/bjp.bp.110.080499

Kim, S. (2015). ppcor: Partial and Semi-Partial (Part) Correlation. R package version 1.1. Retrieved from https://CRAN.R-project.org/package=ppcor

Kramer, I., Simons, C. J., Wigman, J. T., Collip, D., Jacobs, N., Derom, C., . . Wichers, M. (2014). Time-lagged moment-to-moment interplay between negative affect and paranoia: new insights in the affective pathway to psychosis. Schizophrenia bulletin, 40(2), 278-286. doi:10.1093/schbul/sbs194

Lataster, T., Collip, D., Lardinois, M., van Os, J., \& Myin-Germeys, I. (2010). Evidence for a familial correlation between increased reactivity to stress and positive psychotic symptoms. Acta Psychiatrica Scandinavica, 122(5), 395-404. doi:10.1111/j.1600-0447.2010.01566.x

Lataster, T., Valmaggia, L., Lardinois, M., van Os, J., \& Myin-Germeys, I. (2013). Increased stress reactivity: a mechanism specifically associated with the positive symptoms of psychotic disorder. Psychological medicine, 43(7), 1389-1400. doi:10.1017/s0033291712002279

Maiano, C., Normand, C. L., Salvas, M. C., Moullec, G., \& Aimé, A. (2016). Prevalence of school bullying among youth with autism spectrum disorders: A systematic review and meta-analysis. Autism research, 9(6), 601-615. doi:10.1002/aur.1568

Mancini, V., Maeder, J., Bortolin, K., Schneider, M., Schaer, M., \& Eliez, S. (2021). Long-term effects of early treatment with SSRIs on cognition and brain development in individuals with 22q11. 2 deletion syndrome. Translational psychiatry, 11(1), 1-12. doi:10.1038/s41398-021-01456-x

Milic, B., Feller, C., Schneider, M., Debbané, M., \& Loeffler-Stastka, H. (2021). Social cognition in individuals with 22q11. 2 deletion syndrome and its link with psychopathology and social outcomes: a review. BMC psychiatry, 21(1), 1-18. doi:10.1186/s12888-020-02975-5

Miller, T. J., McGlashan, T. H., Rosen, J. L., Somjee, L., Markovich, P. J., Stein, K., \& Woods, S. W. (2002). Prospective diagnosis of the initial prodrome for schizophrenia based on the Structured Interview for Prodromal Syndromes: preliminary evidence of interrater reliability and predictive validity. American Journal of Psychiatry, 159(5), 863-865. doi:10.1176/appi.ajp.159.5.863

Millman, Z. B., Pitts, S. C., Thompson, E., Kline, E. R., Demro, C., Weintraub, M. J., . . Schiffman, J. (2018). Perceived social stress and symptom severity among help-seeking adolescents with versus without clinical high-risk for psychosis. Schizophrenia research, 192, 364-370. doi:10.1016/j.schres.2017.06.002 
Mote, J., \& Fulford, D. (2020). Ecological momentary assessment of everyday social experiences of people with schizophrenia: A systematic review. Schizophrenia research, 216, 56-68. doi:10.1016/j.schres.2019.10.021

Myin-Germeys, I., Delespaul, P., \& van Os, J. (2005). Behavioural sensitization to daily life stress in psychosis. Psychological medicine, 35(5), 733-741. doi:10.1017/s0033291704004179

Myin-Germeys, I., Peeters, F., Havermans, R., Nicolson, N. A., DeVries, M. W., Delespaul, P., \& Van Os, J. (2003). Emotional reactivity to daily life stress in psychosis and affective disorder: an experience sampling study. Acta Psychiatrica Scandinavica, 107(2), 124-131. doi:10.1034/j.1600-0447.2003.02025.x

Myin-Germeys, I., \& van Os, J. (2007). Stress-reactivity in psychosis: evidence for an affective pathway to psychosis. Clinical psychology review, 27(4), 409-424. doi:10.1016/j.cpr.2006.09.005

Myin-Germeys, I., van Os, J., Schwartz, J. E., Stone, A. A., \& Delespaul, P. A. (2001). Emotional reactivity to daily life stress in psychosis. Archives of general psychiatry, 58(12), 1137-1144. doi:10.1001/archpsyc.58.12.1137

Myin-Germeys, I., Kasanova, Z., Vaessen, T., Vachon, H., Kirtley, O., Viechtbauer, W., \& Reininghaus, U. (2018). Experience sampling methodology in mental health research: new insights and technical developments. World Psychiatry, 17(2), 123-132. doi:10.1002/wps.20513

Paetzold, I., Myin-Germeys, I., Schick, A., Nelson, B., Velthorst, E., Schirmbeck, F., . . Reininghaus, U. (2021). Stress reactivity as a putative mechanism linking childhood trauma with clinical outcomes in individuals at ultra-high-risk for psychosis: Findings from the EU-GEI High Risk Study. Epidemiology and psychiatric sciences, 30, e40. doi:10.1017/s2045796021000251

Palmier-Claus, J. E., Dunn, G., \& Lewis, S. W. (2012). Emotional and symptomatic reactivity to stress in individuals at ultra-high risk of developing psychosis. Psychological medicine, 42(5), 10031012. doi:10.1017/s0033291711001929

Patterson, J. M., \& McCubbin, H. I. (1987). Adolescent coping style and behaviors: conceptualization and measurement. Journal of adolescence, 10(2), 163-186. doi:10.1016/s0140-1971(87)800866

Pinheiro, J., Bates, D., \& R Core Team. (2022). Linear and Nonlinear Mixed Effects Models. R package version 3.1-157. Retrieved from https://CRAN.R-project.org/package=nlme

R Core Team. (2020). R: A language and environment for statistical computing. R Foundation for Statistical Computing, Vienna, Austria. Retrieved from https://www.R-project.org/

Rauschenberg, C., Van Os, J., Cremers, D., Goedhart, M., Schieveld, J., \& Reininghaus, U. (2017). Stress sensitivity as a putative mechanism linking childhood trauma and psychopathology in youth's daily life. Acta Psychiatrica Scandinavica, 136(4), 373-388. doi:10.1111/acps.12775

Reininghaus, U., Kempton, M. J., Valmaggia, L., Craig, T. K., Garety, P., Onyejiaka, A., . . . Morgan, C. (2016). Stress Sensitivity, Aberrant Salience, and Threat Anticipation in Early Psychosis: An Experience Sampling Study. Schizophrenia bulletin, 42(3), 712-722. doi:10.1093/schbul/sbv190

Rutter, M., Bailey, A., \& Lord, C. (2003). The social communication questionnaire: Manual: Western Psychological Services.

Sanders, A. F., Hobbs, D. A., Stephenson, D. D., Laird, R. D., \& Beaton, E. A. (2017). Working memory impairments in chromosome 22q11. 2 deletion syndrome: the roles of anxiety and stress physiology. Journal of autism and developmental disorders, 47(4), 992-1005. doi:10.1007/s10803-016-3011-2

Sandini, C., Chambaz, M., Schneider, M., Armando, M., Zöller, D., Schaer, M., . . Eliez, S. (2020). Pituitary dysmaturation affects psychopathology and neurodevelopment in 22q11. 2 Deletion Syndrome. Psychoneuroendocrinology, 113, 104540. doi:10.1016/j.psyneuen.2019.104540

Schneider, M., Debbané, M., Bassett, A. S., Chow, E. W., Fung, W. L., van den Bree, M., ... Eliez, S. (2014). Psychiatric disorders from childhood to adulthood in 22q11.2 deletion syndrome: results from the International Consortium on Brain and Behavior in 22q11.2 Deletion Syndrome. American Journal of Psychiatry, 171(6), 627-639. doi:10.1176/appi.ajp.2013.13070864

Schneider, M., Vaessen, T., van Duin, E. D. A., Kasanova, Z., Viechtbauer, W., Reininghaus, U., . . . Myin-Germeys, I. (2020). Affective and psychotic reactivity to daily-life stress in adults with 22q11DS: a study using the experience sampling method. Journal of Neurodevelopmental Disorders, 12(1), 30. doi:10.1186/s11689-020-09333-2 
Segrin, C., Hanzal, A., Donnerstein, C., Taylor, M., \& Domschke, T. J. (2007). Social skills, psychological well-being, and the mediating role of perceived stress. Anxiety, stress, and coping, 20(3), 321-329. doi:10.1080/10615800701282252

Shaffer, D., Gould, M. S., Brasic, J., Ambrosini, P., Fisher, P., Bird, H., \& Aluwahlia, S. (1983). A children's global assessment scale (CGAS). Archives of general psychiatry, 40(11), 1228-1231. doi:10.1001/archpsyc.1983.01790100074010

Shashi, V., Veerapandiyan, A., Schoch, K., Kwapil, T., Keshavan, M., Ip, E., \& Hooper, S. (2012). Social skills and associated psychopathology in children with chromosome 22q11. 2 deletion syndrome: implications for interventions. Journal of Intellectual Disability Research, 56(9), 865-878. doi:10.1111/j.1365-2788.2011.01477.x

Sladek, M. R., Doane, L. D., Luecken, L. J., \& Eisenberg, N. (2016). Perceived stress, coping, and cortisol reactivity in daily life: A study of adolescents during the first year of college. Biological psychology, 117, 8-15. doi:10.1016/j.biopsycho.2016.02.003

StataCorp. (2019). Stata Statistical Software: Release 16. College Station, TX: StataCorp LLC.

Swillen, A., \& McDonald-McGinn, D. (2015). Developmental trajectories in 22q11.2 deletion. American journal of medical genetics. Part C, Seminars in medical genetics, 169(2), 172-181. doi:10.1002/ajmg.c.31435

Tessner, K. D., Mittal, V., \& Walker, E. F. (2011). Longitudinal study of stressful life events and daily stressors among adolescents at high risk for psychotic disorders. Schizophrenia bulletin, 37(2), 432-441. doi:10.1093/schbul/sbp087

Thissen, D., Steinberg, L., \& Kuang, D. (2002). Quick and easy implementation of the BenjaminiHochberg procedure for controlling the false positive rate in multiple comparisons. Journal of educational and behavioral statistics, 27(1), 77-83. doi:10.3102/10769986027001077

Vaessen, T., van Nierop, M., Decoster, J., Delespaul, P., Derom, C., De Hert, M., . . Thiery, E. (2017). Is sensitivity to daily stress predictive of onset or persistence of psychopathology? European Psychiatry, 45, 167-173. doi:10.1016/j.eurpsy.2017.07.002

van den Bos, E., De Rooij, M., Miers, A. C., Bokhorst, C. L., \& Westenberg, P. M. (2014). Adolescents' increasing stress response to social evaluation: Pubertal effects on cortisol and alpha-amylase during public speaking. Child development, 85(1), 220-236. doi:10.1111/cdev.12118

van der Linden, K., Simons, C., Viechtbauer, W., Ottenheijm, E., van Amelsvoort, T., \& Marcelis, M. (2021). A momentary assessment study on emotional and biological stress in adult males and females with autism spectrum disorder. Scientific reports, 11(1), 14160. doi:10.1038/s41598021-93159-y

van der Steen, Y., Gimpel-Drees, J., Lataster, T., Viechtbauer, W., Simons, C. J. P., Lardinois, M., . . . Myin-Germeys, I. (2017). Clinical high risk for psychosis: the association between momentary stress, affective and psychotic symptoms. Acta Psychiatrica Scandinavica, 136(1), 63-73. doi:10.1111/acps. 12714

van Duin, E. D. A., Vaessen, T., Kasanova, Z., Viechtbauer, W., Reininghaus, U., Saalbrink, P., ... Myin-Germeys, I. (2019). Lower cortisol levels and attenuated cortisol reactivity to daily-life stressors in adults with 22q11.2 deletion syndrome. Psychoneuroendocrinology, 106, 85-94. doi:10.1016/j.psyneuen.2019.03.023

Veling, W., Pot-Kolder, R., Counotte, J., van Os, J., \& van der Gaag, M. (2016). Environmental social stress, paranoia and psychosis liability: a virtual reality study. Schizophrenia bulletin, 42(6), 1363-1371. doi:10.1093/schbul/sbw031

Vermetten, E., Vythilingam, M., Schmahl, C., DE Kloet, C., Southwick, S. M., Charney, D. S., \& Bremner, J. D. (2006). Alterations in stress reactivity after long-term treatment with paroxetine in women with posttraumatic stress disorder. Annals of the New York Academy of Sciences, 1071, 184-202. doi:10.1196/annals.1364.014

Vingerhoets, C., van Oudenaren, M. J. F., Bloemen, O. J. N., Boot, E., van Duin, E. D. A., Evers, L. J. M., . . . van Amelsvoort, T. (2019). Low prevalence of substance use in people with 22q11.2 deletion syndrome. The British journal of psychiatry, 215(5), 661-667. doi:10.1192/bjp.2018.258

Vorstman, J. A. S., Morcus, M. E. J., Duijff, S. N., Klaassen, P. W. J., Heineman-de Boer, J. A., Beemer, F. A., . . . van Engeland, H. (2006). The 22q11.2 deletion in children: high rate of autistic 
disorders and early onset of psychotic symptoms. Journal of the American Academy of Child and Adolescent Psychiatry, 45(9), 1104-1113. doi:10.1097/01.chi.0000228131.56956.c1

Wechsler, D. (2008). Wechsler Adult Intelligence Scale (4th ed.). San Antonio, TX: Pearson Assessment.

Wechsler, D. (2014). Wechsler Intelligence Scale for Children-Fifth Edition technical and interpretive manual. San Antonio, TX: NCS Pearson.

Werner, K., \& Gross, J. J. (2010). Emotion regulation and psychopathology: A conceptual framework. In A. M. Kring \& D. M. Sloan (Eds.), Emotion regulation and psychopathology: A transdiagnostic approach to etiology and treatment. (pp. 13-37). New York, NY: The Guildford Press.

Wilson, N. J., Chen, Y. W., Mahoney, N., Buchanan, A., Marks, A., \& Cordier, R. (2020). Experience sampling method and the everyday experiences of adults with intellectual disability: A feasibility study. Journal of applied research in intellectual disabilities, 33(6), 1328-1339. doi: $10.1111 /$ jar.12753 


\section{Supplementary material}

\section{Methods}

\section{Ecological Momentary Assessment (EMA)}

For EMA data collection, the RealLife Exp application (associated to the Lifedatacorp platform) was installed on the smartphone of each participant. If a participant did not own a smartphone $(n=3)$, the application was installed on a tablet or a family member's smartphone that was loaned to the participant during the duration of the study. We also ensured that the participant had good knowledge of the functioning of the tablet/smartphone. We used a semi-random signal-contingent sampling scheme with eight notifications per day (ranging between 7:30 AM and 10:00 PM) for six consecutive days, resulting in a maximum of 48 beeps per person. At each beep, participants were instructed to respond to a short questionnaire on the application on their mobile phone. A window of at least 30 minutes was scheduled between two consecutive notifications. Participants had 15 minutes to respond to a notification before it expired. During the installation, participants were briefed extensively about the EMA protocol and completed a test questionnaire with the examiner to make sure that they understood all the questions as well as the 7-point Likert scale or multiple-choice answers for giving their responses. During the EMA period, the participants' compliance was monitored and they were contacted several times by a member of the research team to keep them motivated for the protocol. Questionnaires completed in more than 15 minutes were excluded. In addition, responses that were completed in less than one minute were examined individually, and those with a clear pattern of response (i.e., the same response to each item) were excluded because of potential careless responding. In line with previous studies (e.g., MyinGermeys, van Os, Schwartz, Stone, \& Delespaul, 2001), only participants who completed a full questionnaire for at least one-third of the beeps were included in the analyses.

\section{EMA measures}

\section{Affects and momentary psychotic experiences}

Positive and negative affects as well as momentary psychotic experiences were assessed with several items, each measured on a scale from 1 ("not at all") to 7 ("extremely"). Within-person centered data were entered in a factor analysis with oblimin rotation to examine factor structure of the items. The results revealed a 3-factor structure with eigenvalues greater than 1 :

Positive affects (PA) were assessed using the mean score of four items: "I feel relaxed", "I feel content/cheerful", "I feel excited", "I have confidence in myself" (respective loadings were 0.52, 0.74, 0.78 and 0.52 ; Cronbach's $\alpha=0.6$ ). 
Negative affects (NA) were assessed using the mean score of five items: "I feel alone", "I feel anxious", "I feel irritated/angry", "I feel sad", "I feel that others don't like me" (respective loadings were $0.44,0.43,0.65,0.72$ and 0.71 ; Cronbach's $\alpha=0.6$ ).

Momentary psychotic experiences were assessed using the mean score of three items: "I feel like I have to be on my guard, that I'm not safe", "I feel like my imagination is mixing with reality", "I feel like I'm hearing or seeing things that other people don't perceive" (respective loadings were 0.62, 0.65 and 0.77 ; Cronbach's $\alpha=0.43$ ). This method was found to be a reliable measure of psychotic experiences (Feller, Ilen, Eliez, \& Schneider, 2021)

\section{Stress}

To measure daily-life stress in different contexts, a similar approach to earlier studies was applied (Myin-Germeys et al., 2001). All items were measured on a scale from 1 (not at all) to 7 (extremely).

Social stress. When participants reported being in company of others, they were asked to evaluate their subjective experience of this company. The mean score of following items was used to represent social stress (Cronbach's $\alpha=0.54)$ : "I would prefer to be alone", "This company is pleasant" (reversed score for analyses), "I feel judged by this/these person(s)", "I am nervous in the presence of this/these $\operatorname{person}(s) "$.

Activity stress. At each beep, participants were asked to report their current activities. Based on their responses, we divided activities into six categories (adapted from Schneider et al., 2020): 1. Work/school; 2. House-related activities (housework, personal care): 3. Eating/drinking; 4. Social (social contact, online social contact); 5. Leisure (sport, other hobbies, TV, internet, rest); 6. Nothing. Participants were then asked to evaluate their current activity with following items: "This activity is difficult", "I enjoy doing this activity" (reversed score for analyses). The mean score of these two items was used to represent activity-related stress (Cronbach's $\alpha=0.46$ ).

Event stress. Participants were asked to think about the most important event that happened since the last beep and report their subjective experience of this event. To measure event-related stress, the reversed score of the item "This event was enjoyable" was used in the analyses. Initially, we planned to add another item (i.e., "This event was stressful") to the event stress measure but the internal consistency for these items was poor (Cronbach's $\alpha=0.39$ ). Therefore, we decided to use only the item evaluating pleasure of past events that is more in line with what has been done in previous studies (e.g., MyinGermeys et al., 2001). The first beep of the assessment was removed as the item referred to the previous beep, which had not yet occurred.

\section{Clinical evaluation}

To assess the presence of psychiatric disorders, the Diagnostic Interview for Children and Adolescents - Revised (DICA-IV) (Reich, 2000) or the Schedule for Affective Disorders and Schizophrenia for School-Age Children - Present and Lifetime version DSM-5 (K-SADS-PL-5) (Kaufman et al., 1997) 
were used with participants below 18 years old. Adults were assessed with the Structured Clinical Interview for Axis I DSM-IV/ DSM-5 (SCID) (Spitzer, Williams, Gibbon, \& First, 1992). All the interviews were conducted by a trained child psychiatrist (SE). Psychiatric comorbidity was measured as the sum of current psychiatric diagnoses, in line with previous studies (Sandini et al., 2020).

\section{Deviations from the co-registration}

The following deviations from the co-registration should be noted: first, for the co-registration, the EMA variables were defined a priori but we decided to verify the internal consistency of the scales and perform a factor analysis to verify the loadings of items, which led to some modifications in the composition of the EMA variables. Second, because we assumed that the study would have been too large, we did not conduct analyses about the effect of social context for affects or social stress described in the co-registration, as they were not directly linked to our hypotheses. Third, we conducted a supplementary analysis about the possible effect of selective serotonin reuptake inhibitors (SSRIs) on the stress reactivity in the clinical group. Forth, when investigating the moderation effect of coping, we used LRT to assess model fit after adding a group to the model as a three-way interaction. Finally, as the distribution of the score of SIPS positive psychotic symptoms was positively skewed, we used Spearman rank correlations instead of regression models to examine the associations between stress reactivity and psychopathology. We also decided to include negative psychotic symptoms to our analyses to be able to investigate correlations between stress reactivity and not only positive but also negative symptoms. 


\section{Results}

Possible effects of age and sex on stress in different contexts or on affective reactivity to different types of stressors were examined in the entire sample. No effects of either age or sex were observed. Results are reported in Table S1.

Supplementary Table S1. Effects of age and sex on stress and stress reactivity measures

\begin{tabular}{llccc}
\hline & \multicolumn{1}{c}{ Age } & \multicolumn{1}{c}{ Sex } \\
& \multicolumn{1}{c}{$\beta(95 \% \mathrm{CI})$} & $p$ & \multicolumn{1}{c}{$\beta(95 \% \mathrm{CI})$} & $p$ \\
\hline Social stress & $0.003(-0.02$ to 0.02$)$ & 0.794 & $-0.15(-0.34$ to 0.05$)$ & 0.137 \\
Activity stress & $-0.0008(-0.03$ to 0.02$)$ & 0.953 & $-0.18(-0.39$ to 0.03$)$ & 0.09 \\
Event stress & $-0.01(-0.05$ to 0.03$)$ & 0.565 & $-0.17(-0.5$ to 0.16$)$ & 0.308 \\
Social stress reactivity & $-0.003(-0.03$ to 0.02$)$ & 0.786 & $-0.08(-0.29$ to 0.13$)$ & 0.435 \\
Activity stress reactivity & $0.008(-0.002$ to 0.02$)$ & 0.106 & $0.05(-0.03$ to 0.13$)$ & 0.229 \\
Event stress reactivity & $0.002(-0.005$ to 0.01$)$ & 0.501 & $0.005(-0.06$ to 0.07$)$ & 0.859 \\
\hline
\end{tabular}

As almost half of our clinical participants had a diagnosis of anxiety disorder and a large proportion of them $(n=15)$ used selective serotonin reuptake inhibitors (SSRIs) at the time of testing, an exploratory analysis about the effect of SSRI medication status on stress reactivity was conducted in the 22q11DS group. The effects of the duration and the dose equivalent of SSRI medication were controlled, together with age, gender and EMA period. No effect of medication status on stress reactivity was detected. Results are reported in Table $\mathrm{S} 2$.

Supplementary Table S2. Effect of stress x SSRI interaction on negative affect, controlling for dose equivalent and duration of medication, age, gender and EMA period.

\begin{tabular}{lcc}
\hline & Outcome: negative affects & \\
& $\beta(95 \% \mathrm{CI})$ & $p$ \\
\hline Social stress x SSRI & $0.14(-0.07$ to 0.36$)$ & 0.192 \\
Activity stress x SSRI & $0.04(-0.033$ to 0.12$)$ & 0.264 \\
Event stress x SSRI & $0.07(-0.015$ to 0.153$)$ & 0.108
\end{tabular}

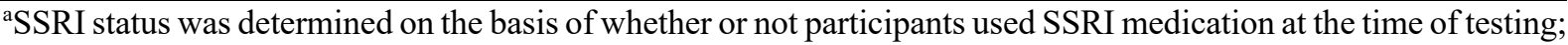
$n=15$ clinical participants with and $n=22$ clinical participants without SSRI medication. 
Correlations between stress reactivity variables and psychopathology variables were investigated using Spearman rank correlations, controlling for the effects of age, sex, IQ and EMA period. Results are reported in Table S3.

Supplementary Table S3. Spearman rank correlation coefficients between stress reactivity and psychopathology variables in 22q11DS group, after controlling for age, sex, IQ and period

\begin{tabular}{|c|c|c|c|c|c|c|}
\hline & 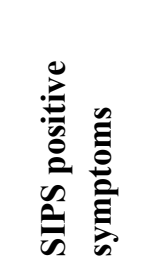 & 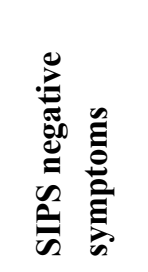 & 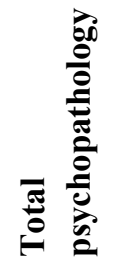 & 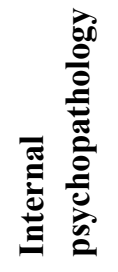 & 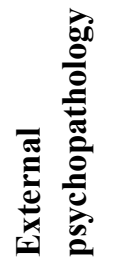 & 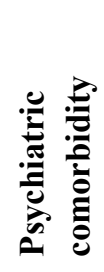 \\
\hline Social stress reactivity & $0,505 * * \dagger$ & $0,516^{* *}$ & 0,251 & 0,048 & 0,177 & 0,081 \\
\hline Activity stress reactivity & $0,372 *$ & 0,200 & $-0,141$ & $-0,24$ & 0,008 & 0,25 \\
\hline Event stress reactivity & 0,205 & $0,410^{*}$ & 0,018 & $-0,010$ & 0,141 & 0,347 \\
\hline
\end{tabular}

${ }^{*} p<0.05,{ }^{* *} p<0.01$

$\dagger \mathrm{p}$-values surviving Benjamini-Hochberg correction (threshold $=0.0083$ )

Finally, the correlation analyses were repeated without univariate outliers (i.e., values $>3$ SD of stress reactivity variables). The results are reported in Table S4.

Supplementary Table S4. Spearman rank correlation coefficients after excluding univariate outliers (social stress reactivity, $n=1$; activity stress reactivity, $n=2$ ) between stress reactivity and psychopathology variables, after controlling for age, sex, IQ and period

\begin{tabular}{|c|c|c|c|c|c|c|}
\hline & 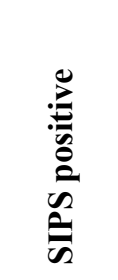 & 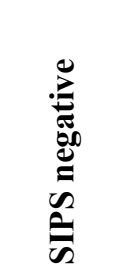 & 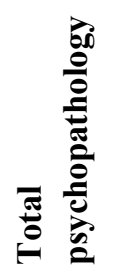 & 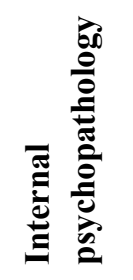 & 尊 & 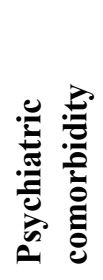 \\
\hline Social stress reactivity & $0,481^{*}$ & $0,551^{* *}$ & 0,196 & 0,068 & 0,107 & 0,069 \\
\hline Activity stress reactivity & $0,345 \dagger$ & 0,169 & $-0,308$ & $-0,417 *$ & $-0,077$ & 0,113 \\
\hline
\end{tabular}
$\dagger p<0.1,{ }^{*} p<0.05,{ }^{* *} p<0.01$

Note: p-values did not survive Benjamini-Hochberg correction 


\section{References}

Feller, C., Ilen, L., Eliez, S., \& Schneider, M. (2021). Psychotic experiences in daily-life in adolescents and young adults with 22q11.2 deletion syndrome: An Ecological Momentary Assessment study. Schizophrenia research, 238, 54-61. doi:10.1016/j.schres.2021.09.024

Kaufman, J., Birmaher, B., Brent, D., Rao, U., Flynn, C., Moreci, P., . . Ryan, N. (1997). Schedule for Affective Disorders and Schizophrenia for School-Age Children-Present and Lifetime Version (K-SADS-PL): initial reliability and validity data. Journal of the American Academy of Child and Adolescent Psychiatry, 36(7), 980-988. doi:10.1097/00004583-199707000-00021

Myin-Germeys, I., van Os, J., Schwartz, J. E., Stone, A. A., \& Delespaul, P. A. (2001). Emotional reactivity to daily life stress in psychosis. Archives of general psychiatry, 58(12), 1137-1144. doi:10.1001/archpsyc.58.12.1137

Reich, W. (2000). Diagnostic interview for children and adolescents (DICA). Journal of the American Academy of Child and Adolescent Psychiatry, 39(1), 59-66. doi:10.1097/00004583-20000100000017

Sandini, C., Chambaz, M., Schneider, M., Armando, M., Zöller, D., Schaer, M., . . Eliez, S. (2020). Pituitary dysmaturation affects psychopathology and neurodevelopment in 22q11. 2 Deletion Syndrome. Psychoneuroendocrinology, 113, 104540. doi:10.1016/j.psyneuen.2019.104540

Schneider, M., Vaessen, T., van Duin, E. D. A., Kasanova, Z., Viechtbauer, W., Reininghaus, U., . . . Myin-Germeys, I. (2020). Affective and psychotic reactivity to daily-life stress in adults with 22q11DS: a study using the experience sampling method. Journal of Neurodevelopmental Disorders, 12(1), 30. doi:10.1186/s11689-020-09333-2

Spitzer, R. L., Williams, J. B., Gibbon, M., \& First, M. B. (1992). The Structured Clinical Interview for DSM-III-R (SCID). I: History, rationale, and description. Archives of general psychiatry, 49(8), 624-629. doi:10.1001/archpsyc.1992.01820080032005 